\title{
Assessment of Policies to Promote People's Environmental Activities
}

\author{
Tetsuo Nishi \\ Tokyo Institute of Technology, 2-12-1-W9-25 Ookayama, Meguro-ku, Tokyo 152-8552, Japan
}

\begin{abstract}
Nowadays, many kinds of environmentally friendly campaigns led by local governments and private companies alike have been conducted in order to increase the pro-environmental behaviors. Unfortunately, these campaigns do not always lead to the upgrading of people's pro-environmental behaviors, because people's behaviors are usually based on various motivations, including economic efficiency, convenience and so on. This article mainly aimed at analyzing the implementing reasons of people's pro-environmental behaviors and finding out policies of promoting people's pro-environmental behaviors. Therefore, the author conducted the internet investigations among male and female respondents over 20 years old, and collected valid responses of more than 1,000 from 2008 till 2014 every year in Japan and also used three communication concepts, which are the direct communication, the indirect communication and the direct and indirect combined communication as a framework for discussing policies of promoting people’s pro-environmental behaviors. As a result of the internet investigations, it was found that non-environmental factors, such as "saving the household", "compliance with social norms" and "health" were bigger than the environmental factors, such as "the prevention of the global warming" and "saving resources" with regard to the implementing reasons of the pro-environmental activities. Actually, the pro-environmental activities often have the non-environmental benefits, such as cost-saving, health and so on. And so, the author suggests that it is effective that upgrading the implementation rate of the pro-environmental activities do not only appeal to the effects of reducing the environmental loading that the activity has (the direct communication), but also to the non-environmental benefits that the activity has, especially it is true to unconcerned people about environmental issues (the indirect communication). In addition, the author emphases that people need to appeal to both the environmental effects and the non-environmental benefits which the activity has, respectively, especially to people with the concern about environmental issues to some extent (the direct and indirect combined communication).
\end{abstract}

Key words: Environmental awareness, incentive, the direct communication, the indirect communication, the direct and indirect combined communication.

\section{Introduction}

In recent years, the environmentally friendly campaigns targeted individuals by local governments and companies alike have been increasing. Even though environmentally friendly products have been sold and the environmental measures targeted at individuals have been implemented, this is always the case that these activities do not reach directly each person's environmentally-oriented behavior. This is due to the fact that consumers tend to choose their behavior based on a variety of factors, including convenience, pleasure, economic efficiency, besides

Corresponding author: Tetsuo Nishi, Ph.D. student, research fields: environmental and food consciousness, social business, social system. environmental-oriented factors. Therefore, it is necessary to clarity various motives which make people choose something and consider the ways which promote ambient behavior.

There are many previous studies on the factors of human behaviors, including the pro-environmental behavior.

The main theories about the relevance of human attitudes and behaviors are "the theory of reasoned action" by Ajzen and Fishbein [1] and "the theory of planned behavior" by Ajzen and Madden [2] and Ajzen [3].

Ajzen and Fishbein [1] have explained the relevance of attitudes and behaviors by assuming the mental factors called "behavioral intentions", 
"attitudes for behavior" and "subjective norms" in the theory of reasoned action. That is, they express that "behavioral intentions" are formed of "attitudes for behavior" and "subjective norms", and as the behavioral intentions become strong, the possibility that the action will be performed becomes higher.

But this theory has the restriction of behaviors which are completely controllable with the individual's behavioral intentions.

Therefore, in the theory of planned behavior, which is a development model from the theory of reasoned action, this limit has been improved by adding the psychological factor called "perceived behavioral control”. The perceived behavioral control means the measurement for evaluation whether it is easy or not to perform the action by the individual's intention in the situation at that time. The perceived behavioral control affects both the behavioral intentions and the implementation of behavior.

However, these theories do not sufficiently explain the inconsistency between pro-environmental attitudes and pro-environmental behaviors.

"The two-phase model" by Hirose [4] and "the dual-process of decision making model” by Ohtomo and Hirose [5] are the typical examples of the theories, which explain above inconsistency.

Hirose [4] expressed that because there is a time lag between the first phase where a person recognizes the importance of environmental problems and the second phase where a person carries out the environmental action, like the purchase of an environmentally friendly product in a shop, thereby a person chooses the different actions from the ones when they have chosen at the first phase. He named such a situation as "the two-phase model".

In addition, Ohtomo and Hirose [5] suggested "the dual-process of decision making model” on the basis of "the two-phase model". They showed that there are two types of decision making processes, namely "reactive decision" and "intentional decision".

In the reactive decision, people have a vague image for each action. Also, when an individual performs the act, he/she judges whether he/she should perform the act which they choose or not, considering others' observational evaluations (including both positive and negative evaluations). This evaluation standard of the act is called "the descriptive norm". On the other hand, in the intentional decision, people hold an explicit sense of purpose. This sense of explicit purpose is called "the aim intention". When an individual performs the act, he/she judges whether he/she should perform the act which they chose or not, in accordance with a prescriptive social norm. This autonomous standard of the act is the subjective norm.

Ohtomo and Hirose [5] explain the dual-process of decision making model as follows. While intentional decision performs actions which promote the environmentally friendly behavior, reactive decision performs actions which restrain the environmentally friendly behavior. Hence, since intentional decision is not always made, the environmentally friendly behavior is not always promoted either. Ohtomo and Hirose [5] explained the reason why the environmental awareness does not always lead to the promotion of the environmentally friendly activities.

These studies clarified the structure and the mechanism of the human actions. However, they do not argue how the environmentally friendly behavior should be promoted under such situations.

In this article, the author will explore the approaches which promote people's ambient behavior by clarifying implementing reasons for ambient behavior, including individuals' environmental awareness, implementation status of ambient behavior, the environmentally related advantages and non-environmental advantages.

\section{Methods}

\subsection{The Internet Survey for People}

In this paper, with the aforementioned studies in mind, it will be argued how we can promote the individuals' environmental behaviors. 
First, the actual conditions of people's environmental awareness and their related factors based on that actual condition will be explained. Then, the methods to promote the environmental friendly activities will be discussed. The following annual internet survey results are used in the study of people's awareness and behavior [6]. The 2008-2014 surveys were conducted by Initiative for Circular Flow Society (ICFS), which was a research group of environmental staff members in Japanese main companies and the author of this paper was the chairman of this group. The surveys were designed in 2008 and have been conducted since then among male and female respondents aged over 20 years old with valid responses of more than 1,000, which meets pre-designed target sample splits in line with the universe. This internet survey was conducted twice in February and June, 2011, respectively, to analyze the difference between before and after the big earthquake happened in March 2011 in Japan. Table 1 shows the periods the survey conducted and the number of samples.

Samples were extracted from INTAGE sample panel based on the quota allocation by area, gender and age in line with the splits of universe. Fifty questions were asked regarding interest in social issues, how often they actually take pro-environmental actions in their daily life and the reasons for their actual actions, what importance they consider at the time of purchasing and so on.

The national population census, which Statistic Bureau, Ministry of Internal Affairs and Communications in Japan have conducted every five years, was used as the universe. The census conducted in 2005 [7] was utilized as the universe of surveys during the period 2009-2011 and the census conducted in 2010 [8] was utilized as the universe of surveys during the period 2012-2014.

Samples have been extracted from INTAGE sample panel, and 800,000 people were based on the quota allocation by gender (male, female), age (20-29, 30-39, 40-49, 50-59, over 60) and area (Hokkaido/Tohoku, Kanto/Keihin, Chubu, Kinki, Chugoku/Shikoku, Kyusyu/Okinawa) in line with the splits of universe. Table 1 shows the requested sample number, the collected sample number and the collected rate in each survey.

Tables 2-4 show the comparison between the collected rate of the internet survey in 2014 and the population rate of the census in 2010 by gender, age

Table 1 Research design and result conducted.

\begin{tabular}{lllll}
\hline Year & Period & Requested sample number & Collected sample number & Collected rate (\%) \\
\hline 2008 & March 14-18 & 3,200 & 1,236 & 38.6 \\
2009 & February 20-24 & 3,200 & 1,042 & 33.8 \\
2010 & February 23-27 & 4,370 & 1,021 & 23.4 \\
2011 & February 24-28 & 4,370 & 1,261 & 28.9 \\
2011 & June 9-13 & 3,395 & 1,421 & 41.9 \\
2012 & February 29-March 2 & 4,540 & 1,264 & 27.8 \\
2013 & March 5-7 & 4,448 & 1,262 & 28.4 \\
2014 & March 20-24 & 5,097 & 1,268 & 24.9 \\
\hline
\end{tabular}

Source: Initiative for Circular Flow Society (ICFS), 2014 [6].

Table 2 Comparison between the internet survey in 2014 and the census in 2010 by gender.

\begin{tabular}{lllll}
\hline Gender & Collected sample number & Collected rate (\%) & Population number by census & Population rate (\%) \\
\hline Male & 612 & 48.3 & $50,045,385$ & 48.0 \\
Female & 656 & 51.7 & $54,168,743$ & 52.0 \\
\hline Total & 1,268 & 100.0 & $104,214,128$ & 100.0 \\
\hline
\end{tabular}

Source: Initiative for Circular Flow Society (ICFS), 2014 [6] and Statistic Bureau, Ministry of Internal Affairs and Communications, $2010[8]$. 
Table 3 Comparison between the internet survey in 2014 and the census in 2010 by age.

\begin{tabular}{lllll}
\hline Age & Collected sample number & Collected rate (\%) & Population number by census & Population rate (\%) \\
\hline $20-29$ & 185 & 14.6 & $13,720,134$ & 13.2 \\
$30-39$ & 208 & 16.4 & $18,127,846$ & 17.4 \\
$40-49$ & 236 & 18.6 & $16,774,981$ & 16.1 \\
$50-59$ & 204 & 16.1 & $16,308,233$ & 15.6 \\
Over 60 & 435 & 34.3 & $39,282,934$ & 37.7 \\
\hline Total & 1,268 & 100.0 & $104,214,128$ & 100.0 \\
\hline
\end{tabular}

Source: Initiative for Circular Flow Society (ICFS), 2014 [6] and Statistic Bureau, Ministry of Internal Affairs and Communications, 2010 [8].

Table 4 Comparison between the internet survey in 2014 and the census in 2010 by area.

\begin{tabular}{lllll}
\hline Area & Collected sample number & Collected rate (\%) & Population number by census & Population rate (\%) \\
\hline Hokkaido/Tohoku & 163 & 12.9 & $12,218,199$ & 11.7 \\
Kanto/Keihin & 410 & 32.3 & $35,598,740$ & 34.2 \\
Chubu & 228 & 18.0 & $18,360,182$ & 17.6 \\
Kinki & 189 & 14.9 & $16,919,182$ & 16.2 \\
Chugoku/Shikoku & 141 & 11.1 & $9,391,760$ & 9.0 \\
Kyushu/Okinawa & 137 & 10.8 & $11,726,065$ & 11.3 \\
\hline Total & 1,268 & 100.0 & $104,214,128$ & 100.0 \\
\hline
\end{tabular}

Source: Initiative for Circular Flow Society (ICFS), 2014 [6] and Statistic Bureau, Ministry of Internal Affairs and Communications 2010 [8].

Following shows prefectures which each area includes:

Hokkaido/Tohoku: Hokkaido, Aomori, Iwate, Miyagi, Akita, Yamagata, Fukushima;

Kanto/Keihin: Ibaraki, Tochigi, Gunma, Saitama, Chiba, Tokyo, Kanagawa, Yamanashi;

Chubu: Niigata, Toyama, Ishikawa, Fukui, Nagano, Gifu, Shizuoka, Aichi, Mie;

Kinki: Shiga, Kyoto, Osaka, Hyogo, Nara, Wakayama;

Chugoku/Shikoku: Tottori, Shimane, Okayama, Hiroshima, Yamaguchi, Tokushima, Kagawa, Ehime, Kochi;

Kyusyu/Okinawa: Fukuoka, Saga, Nagasaki, Kumamoto, Oita, Miyazaki, Kagoshima, Okinawa.

and area. The composition ratio of the collection sample of the internet survey and the population composition ratio of the national population census are almost similar. The comparison ratios of the internet surveys from 2009 till 2013 and the population composition ratio of the census are approximately similar as in 2014.

\subsection{Three Communication Concepts}

Three communication concepts, properly, which are the direct communication, the indirect communication, and the direct and indirect combined communication, were suggested in this paper as the framework for discussing the policy for promoting people's environmental activities.

The direct communication is an important method for solving an actual problem brought by an action, which leads to the following action. In other words, it plays an important role in appealing for the importance of the environmental problem resulting in the environmentally friendly behaviors by people.

The indirect communication is a method dealing with an actual problem that will lead to the convenience for which a given person hopes, resulting in an action followed rather than deepening the understanding of the problem needed for solution. By applying this method to a solution to the environmental issues rather than convincing people of a solution to the environmental issues, various advantages, including economic efficiency, will be realized, resulting in being beneficial to the environmental issues.

The direct and indirect combined communication is the combination of the direct communication and the 
indirect communication. By taking both advantages of the direct and indirect communications, they are beneficial to the environment and enable to the realization of the conveniences, such as economic efficiency. As a result, they will promote an action beneficial to the environmental issues.

Then how the environmentally friendly behavior should be promoted will be argued by using these three types of communications.

\section{Results and Discussion}

\subsection{People's Concerns about the Social Issues}

Table 5 shows the interest in Japanese social issues, which was clear from the results of the internet investigations that the author carried out from 2008 till 2014 [9]. In the investigation, each item and the answer of all the items which were interesting the respondents were listed.

In the 2014 survey, the respondents showed their greatest interest in the pension social security issue at $51.0 \%$, and the domestic economic issues at $45.3 \%$, the energy issues at $39.7 \%$, low birthrate and aging problem at $37.2 \%$, natural disaster earthquake measures at $36.5 \%$, the global environment problem at $27.4 \%$, and food problem at $21.2 \%$.

Lehman Brothers' collapse [10] happened in September 2008 in the United States and afterward the recession period prolonged. Since 2008, the issues of pension social security and domestic economy monopolized the first place and the second place, respectively, and became the most highly concerned issues.

In addition, in March 2011, East Japan great earthquake disaster [11] occurred in the Tohoku district. Therefore, in the survey result of June 2011 in comparison with in the survey result of February 2011, the interest in measures for both natural disasters and earthquakes rose from $30.1 \%$ to $47.9 \%$ and the interest in the energy increased from $30.4 \%$ to $54.0 \%$. However, the global environmental problems were up only $1.8 \%$ from $37.5 \%$ to $39.3 \%$, and the food issues were down $7.3 \%$ from $37.0 \%$ to $29.7 \%$. It is assumed that the great earthquake did not affect people's interest about the global environmental problem and the food problem.

In 2008 when the G8 Hokkaido Toyako Summit conference [12] was held in Lake Toya of Hokkaido, the respondents of $54.0 \%$ answered that they showed the interest in the global environment. But the response ratio of the environmental problem decreased year by year, and in 2014 the response rate of the environmental problem fell down to $27.4 \%$.

In addition, where the ratio of a person interested in the food problem was $51.0 \%$ in 2008 , it dropped to 21.1\% in 2014. It became high from 2007 and 2008, because food poisoning occurred due to the fact that insecticide and pesticide residue were included in the frozen Gyoza and frozen vegetables imported from China in 2007 and 2008 [13]. But, the percentages of food problem decreased, because such major problems did not occur again after that.

Table 5 Trends of people's concerns about the social issues.

\begin{tabular}{lllllllll}
\hline Issues & 2008 & 2009 & 2010 & Feb 2011 & Jun 2011 & 2012 & 2013 & 2014 \\
\hline Pension and social security problem & 61.7 & 61.0 & 62.2 & 58.8 & 55.4 & 63.4 & 54.0 & 51.0 \\
Domestic economy and business problem & 61.9 & 63.9 & 62.3 & 55.4 & 54.9 & 46.8 & 52.1 & 45.3 \\
Energy problem & 42.2 & 38.8 & 33.7 & 30.4 & 54.0 & 42.8 & 43.0 & 39.7 \\
Decreasing birthrate and aging society & 46.5 & 43.1 & 46.3 & 43.7 & 37.9 & 42.6 & 37.2 & 37.2 \\
problem & & & & & & 37.1 \\
Disaster and earthquake problem & 29.6 & 29.0 & 26.2 & 30.1 & 47.9 & 44.6 & 37.8 & 36.5 \\
Environmental problem & 54.0 & 48.0 & 45.0 & 37.5 & 39.3 & 35.7 & 31.9 & 27.4 \\
Food problem & 51.0 & 41.3 & 29.9 & 37.0 & 29.7 & 25.0 & 24.8 & 21.2 \\
\hline
\end{tabular}

Source: Initiative for Circular Flow Society (ICFS), 2014 [6]. 
Anyway, the interest in the issues, such as the global environment and food problems, have continued lower in comparison with the economic issues and so on.

\subsection{The Implementation Rate of the Pro-environmental} Activities

Table 6 shows the implementation rate of various environmental activities during the period of 2008-2014.

In 2014, "separating garbage” showed the highest implementation rate and $81.7 \%$ of people responded that they implemented, followed by "turning off electricity as often as possible when not used" (72.1\%), then "bringing their own bags and declining a shopping bag provided by a shop" (61.8\%), "adjusting a room temperature with switch" (60.6\%) and "using refillable products" (60.6\%).

Implementation rate of "separating garbage" was always the highest during the period of 2008-2014. In each year, more than $80 \%$ of people reported their actual implementation. And "turning off electricity as often as possible when the electricity was not used" was the second highest during the same period and more than $70 \%$ of people reported their actual implementation.

However, implementation rate of each activity remains almost at the same level or shows a little decreasing trend. For example, when compared the data of 2010 and 2014, all the activities decreased, except that "being conscious of cool biz and warm biz" increased $1.4 \%$. In particular, implementation rate of "using refillable products" went down by $11.6 \%$ and "try not buying too much and using the leftovers" went down by $8.2 \%$. Nowadays, it is a big issue how we can raise the implementation rate of the environmental activities.

\subsection{The Implementation Reasons of Environmentally Friendly Activities}

Table 7 shows the implementation reason of the pro-environmental activities in 2014.

With regard to the implementation reason of "separating garbage", "for saving of resources" was the biggest reason with $57.0 \%$ of implementation which people reported their actual implementation, followed by "for recycling promotion" (53.8\%) and "for it was a social rule" (53.2\%). With regard to the implementation reason of "turning off electricity as often as possible when not used", "for saving of the family budget" was the biggest reason and $76.7 \%$ of people reported their actual implementation, followed by "for saving of resources" (54.6\%) and "for prevention of the global warming" (45.7\%).

With regard to "separating garbage" and "bringing a shopper's own bags instead of a free plastic shopping bag offered by a shop", "for saving of resources" is the biggest reason for people's actual implementation, $57.0 \%$ and $69.5 \%$, respectively. With regard to "being conscious of cool biz and warm biz", "for prevention of the global warming" is the biggest reason (54.7\%) for people's actual implementation. But with regard to other environmentally friendly activities, like "turning off electricity as often as possible when not used”, "adjusting room temperature with a thermostat" and so on, "for saving of the family budget" is the top reason for people's actual implementation.

As for "separating garbage", "because of a social obligation" is the third biggest reason and the rate is $53.2 \%$.

As for "adjusting room temperature with a thermostat" and "being conscious of cool biz and warm biz", "for a health reason" is the fourth biggest reason and the former rate is $22.1 \%$ and the latter is $36.4 \%$, respectively. Like this, the reason why an environmental activity is chosen does not always aim at the reduction of the environmental load, such as prevention of the global warming and saving of resources. 
Table 6 Trend of the implementation rate of the pro-environmental activities.

\begin{tabular}{|c|c|c|c|c|c|c|c|c|c|}
\hline Pro-environmental activities & 2008 & 2009 & 2010 & Feb 2011 & Jun 2011 & 2012 & 2013 & 2014 & $\begin{array}{l}\text { Difference of } 2010 \\
\text { and } 2014\end{array}$ \\
\hline Separating garbage & 85.0 & 86.3 & 85.9 & 84.0 & 80.7 & 80.3 & 81.6 & 81.7 & -4.2 \\
\hline Turning off electricity when not used & 73.8 & 75.5 & 75.7 & 72.4 & 76.6 & 70.6 & 75.4 & 72.1 & -3.6 \\
\hline $\begin{array}{l}\text { Bringing a shopper's own bag instead of a free plastic bag } \\
\text { offered by a shop }\end{array}$ & 51.2 & 60.2 & 64.5 & 58.3 & 63.1 & 62.7 & 61.8 & 61.8 & -2.7 \\
\hline Adjusting room temperature with a thermostat when not used & 61.8 & 64.8 & 63.3 & 60.7 & 61.7 & 58.9 & 61.9 & 60.6 & -2.7 \\
\hline Using refillable products & - & 70.6 & 72.2 & 64.0 & 67.6 & 66.1 & 61.8 & 60.6 & -11.6 \\
\hline Saving bath water and tap water & 61.9 & 59.9 & 60.0 & 58.2 & 57.6 & 53.3 & 55.9 & 55.3 & -4.7 \\
\hline Using products carefully for a long term to be usable & 57.1 & 54.9 & 55.0 & 50.5 & 51.0 & 49.4 & 48.7 & 49.8 & -5.2 \\
\hline Being conscious of cool biz and warm biz & - & 35.9 & 37.8 & 32.0 & 36.5 & 31.4 & 36.0 & 39.2 & 1.4 \\
\hline Getting rid of overbuying and using the leftovers & - & 43.5 & 40.8 & 36.5 & 36.7 & 41.0 & 34.4 & 32.6 & -8.2 \\
\hline Reducing standby mode electricity consumption & - & 38.9 & 37.4 & 30.7 & 40.2 & 42.6 & 34.7 & 30.9 & -6.5 \\
\hline
\end{tabular}

Source: Initiative for Circular Flow Society (ICFS), 2014 [6].

Table 7 The implementation reasons of the environmentally friendly activities in 2014.

\begin{tabular}{|c|c|c|c|c|c|c|c|c|c|c|c|}
\hline \multirow[b]{2}{*}{ Activities } & \multicolumn{11}{|c|}{ Implementation reasons } \\
\hline & $\begin{array}{l}\text { For prevention } \\
\text { of the global } \\
\text { warming }\end{array}$ & $\begin{array}{l}\text { For saving of } \\
\text { resources }\end{array}$ & $\begin{array}{l}\text { For recycling } \\
\text { promotion }\end{array}$ & $\begin{array}{l}\text { For reduction of } \\
\text { the family } \\
\text { garbage }\end{array}$ & $\begin{array}{l}\text { For saving of } \\
\text { the family } \\
\text { budget }\end{array}$ & For health & $\begin{array}{l}\text { For getting a } \\
\text { sense of } \\
\text { satisfaction }\end{array}$ & $\begin{array}{l}\text { For it is a } \\
\text { social } \\
\text { rule }\end{array}$ & $\begin{array}{l}\text { For a } \\
\text { neighbor } \\
\text { does it }\end{array}$ & Other & $\begin{array}{l}\text { There is not } \\
\text { the reason in } \\
\text { particular }\end{array}$ \\
\hline Separating garbage & 31.8 & 57.0 & 53.8 & 45.0 & 16.7 & 6.5 & 14.1 & 53.2 & 4.8 & 1.1 & 2.4 \\
\hline Turning off electricity when not used & 45.7 & 54.6 & 5.0 & 3.1 & 76.7 & 3.9 & 14.9 & 12.4 & 1.8 & 1.3 & 1.2 \\
\hline $\begin{array}{l}\text { Bringing a shopper's own bag instead of } \\
\text { a free plastic bag offered by a shop }\end{array}$ & 25.1 & 69.5 & 22.6 & 49.1 & 42.0 & 1.9 & 20.4 & 18.0 & 4.6 & 1.1 & 2.4 \\
\hline $\begin{array}{l}\text { Adjusting room temperature with a } \\
\text { thermostat when not used }\end{array}$ & 61.1 & 46.8 & 4.6 & 2.1 & 80.4 & 22.1 & 18.2 & 11.7 & 2.0 & 1.0 & 1.3 \\
\hline Using refillable products & 20.7 & 65.6 & 29.4 & 61.7 & 66.5 & 2.6 & 17.1 & 6.1 & 1.4 & 0.3 & 0.9 \\
\hline Saving bath water and tap water & 21.3 & 65.3 & 6.1 & 5.3 & 80.2 & 3.6 & 18.8 & 10.8 & 2.0 & 0.9 & 1.0 \\
\hline $\begin{array}{l}\text { Using products carefully for a long term } \\
\text { to be usable }\end{array}$ & 19.5 & 62.2 & 20.4 & 45.3 & 69.6 & 4.7 & 26.6 & 8.5 & 1.3 & 1.4 & 3.3 \\
\hline $\begin{array}{l}\text { Being conscious of cool biz and warm } \\
\text { biz }\end{array}$ & 54.7 & 41.6 & 4.4 & 2.4 & 46.1 & 36.4 & 24.1 & 18.7 & 6.8 & 0.8 & 2.8 \\
\hline $\begin{array}{l}\text { Getting rid of overbuying and using the } \\
\text { leftovers }\end{array}$ & 18.1 & 52.7 & 10.9 & 65.7 & 82.4 & 13.3 & 25.1 & 6.0 & 1.4 & 1.4 & 1.4 \\
\hline $\begin{array}{l}\text { Reducing standby mode electricity } \\
\text { consumption }\end{array}$ & 52.0 & 59.4 & 5.1 & 3.6 & 86.0 & 2.8 & 23.0 & 11.2 & 2.6 & 0.5 & 1.0 \\
\hline
\end{tabular}

Source: Initiative for Circular Flow Society (ICFS), 2014 [6] 
Table 8 Comparison of the implementation reasons of environmentally friendly activities between 2010 and 2014.

\begin{tabular}{|c|c|c|c|c|c|c|c|c|c|c|c|c|}
\hline \multirow{2}{*}{ Activities } & & \multicolumn{11}{|c|}{ Implementation reasons } \\
\hline & & $\begin{array}{l}\text { For prevention } \\
\text { of the global } \\
\text { warming }\end{array}$ & $\begin{array}{l}\text { For saving of } \\
\text { resources }\end{array}$ & $\begin{array}{l}\text { For recycling } \\
\text { promotion }\end{array}$ & $\begin{array}{l}\text { For reduction } \\
\text { of the family } \\
\text { garbage }\end{array}$ & $\begin{array}{l}\text { For saving of } \\
\text { the family } \\
\text { budget }\end{array}$ & For health & $\begin{array}{l}\text { For getting a } \\
\text { sense of } \\
\text { satisfaction }\end{array}$ & $\begin{array}{l}\text { For it is a } \\
\text { social } \\
\text { rule }\end{array}$ & $\begin{array}{l}\text { For a } \\
\text { neighbor } \\
\text { does it }\end{array}$ & Other & $\begin{array}{l}\text { There is not } \\
\text { reason in } \\
\text { particular }\end{array}$ \\
\hline \multirow{3}{*}{ Separating garbage } & 2010 & 17.3 & 35.1 & 52.6 & 32.8 & 5.4 & 1.4 & 12.0 & 57.7 & 5.0 & 0.8 & 1.4 \\
\hline & 2014 & 31.8 & 57.0 & 53.8 & 45.0 & 16.7 & 6.5 & 14.1 & 53.2 & 4.8 & 1.1 & 2.4 \\
\hline & Difference & 14.5 & 21.9 & 1.2 & 12.2 & 11.3 & 5.1 & 2.1 & -4.5 & -0.2 & 0.3 & 1.0 \\
\hline \multirow{3}{*}{$\begin{array}{l}\text { Turning off electricity when } \\
\text { not used }\end{array}$} & 2010 & 39.7 & 45.7 & 1.2 & 0.8 & 81.1 & 0.6 & 12.2 & 3.6 & 1.4 & 0.3 & 1.2 \\
\hline & 2014 & 45.7 & 54.6 & 5.0 & 3.1 & 76.7 & 3.9 & 14.9 & 12.4 & 1.8 & 1.3 & 1.2 \\
\hline & Difference & 6.0 & 8.9 & 3.8 & 2.3 & -4.4 & 3.3 & 2.7 & 8.8 & 0.4 & 1.0 & 0.0 \\
\hline \multirow{3}{*}{$\begin{array}{l}\text { Bringing a shopper’s own } \\
\text { bag instead of a free plastic } \\
\text { bag offered by a shop }\end{array}$} & 2010 & 27.0 & 61.3 & 13.7 & 38.5 & 29.6 & 0.8 & 21.5 & 16.5 & 9.3 & 1.5 & 1.2 \\
\hline & 2014 & 25.1 & 69.5 & 22.6 & 49.1 & 42.0 & 1.9 & 20.4 & 18.0 & 4.6 & 1.1 & 2.4 \\
\hline & Difference & -1.9 & 8.2 & 8.9 & 10.6 & 12.4 & 1.1 & -1.1 & 1.5 & -4.7 & -0.4 & 1.2 \\
\hline \multirow{3}{*}{$\begin{array}{l}\text { Adjusting room temperature } \\
\text { with a thermostat when not } \\
\text { used }\end{array}$} & 2010 & 51.9 & 39.0 & 0.8 & 0.9 & 78.2 & 18.9 & 11.5 & 4.3 & 1.5 & 0.5 & 1.1 \\
\hline & 2014 & 61.1 & 46.8 & 4.6 & 2.1 & 80.4 & 22.1 & 18.2 & 11.7 & 2.0 & 1.0 & 1.3 \\
\hline & Difference & 9.2 & 7.8 & 3.8 & 1.2 & 2.2 & 3.2 & 6.7 & 7.4 & 0.5 & 0.5 & 0.2 \\
\hline \multirow{3}{*}{ Using refillable products } & 2010 & 16.1 & 51.2 & 15.2 & 51.4 & 61.6 & 0.9 & 11.1 & 2.4 & 1.5 & 0.1 & 1.9 \\
\hline & 2014 & 20.7 & 65.6 & 29.4 & 61.7 & 66.5 & 2.6 & 17.1 & 6.1 & 1.4 & 0.3 & 0.9 \\
\hline & Difference & 4.6 & 14.4 & 14.2 & 10.3 & 4.9 & 1.7 & 6.0 & 3.7 & -0.1 & 0.2 & -1.0 \\
\hline \multirow{3}{*}{$\begin{array}{l}\text { Saving bath water and tap } \\
\text { water }\end{array}$} & 2010 & 19.2 & 55.3 & 2.0 & 1.5 & 81.7 & 0.7 & 12.9 & 3.6 & 1.3 & 0.3 & 0.5 \\
\hline & 2014 & 21.3 & 65.3 & 6.1 & 5.3 & 80.2 & 3.6 & 18.8 & 10.8 & 2.0 & 0.9 & 1.0 \\
\hline & Difference & 2.1 & 10.0 & 4.1 & 3.8 & -1.5 & 2.9 & 5.9 & 7.2 & 0.7 & 0.6 & 0.5 \\
\hline \multirow{3}{*}{$\begin{array}{l}\text { Using products carefully for } \\
\text { a long term to be usable }\end{array}$} & 2010 & 14.6 & 49.3 & 7.7 & 31.1 & 66.2 & 0.9 & 21.5 & 2.8 & 1.1 & 1.2 & 3.4 \\
\hline & 2014 & 19.5 & 62.2 & 20.4 & 45.3 & 69.6 & 4.7 & 26.6 & 8.5 & 1.3 & 1.4 & 3.3 \\
\hline & Difference & 4.9 & 12.9 & 12.7 & 14.2 & 3.4 & 3.8 & 5.1 & 5.7 & 0.2 & 0.2 & -0.1 \\
\hline \multirow{3}{*}{$\begin{array}{l}\text { Being conscious of cool biz } \\
\text { and warm biz }\end{array}$} & 2010 & 42.5 & 25.6 & 1.6 & 1.8 & 41.5 & 29.3 & 14.5 & 10.4 & 5.7 & 0.8 & 3.6 \\
\hline & 2014 & 54.7 & 41.6 & 4.4 & 2.4 & 46.1 & 36.4 & 24.1 & 18.7 & 6.8 & 0.8 & 2.8 \\
\hline & Difference & 12.2 & 16.0 & 2.8 & 0.6 & 4.6 & 7.1 & 9.6 & 8.3 & 1.1 & 0.0 & -0.8 \\
\hline \multirow{3}{*}{$\begin{array}{l}\text { Getting rid of overbuying } \\
\text { and using the leftovers }\end{array}$} & 2010 & 16.3 & 40.0 & 5.8 & 54.7 & 78.9 & 7.4 & 18.5 & 2.6 & 1.0 & 0.5 & 1.0 \\
\hline & 2014 & 18.1 & 52.7 & 10.9 & 65.7 & 82.4 & 13.3 & 25.1 & 6.0 & 1.4 & 1.4 & 1.4 \\
\hline & Difference & 1.8 & 12.7 & 5.1 & 11.0 & 3.5 & 5.9 & 6.6 & 3.4 & 0.4 & 0.9 & 0.4 \\
\hline \multirow{3}{*}{$\begin{array}{l}\text { Reducing standby mode } \\
\text { electricity consumption }\end{array}$} & 2010 & 44.8 & 46.9 & 3.4 & 2.4 & 83.8 & 1.3 & 14.4 & 3.9 & 1.0 & 0.8 & 0.8 \\
\hline & 2014 & 52.0 & 59.4 & 5.1 & 3.6 & 86.0 & 2.8 & 23.0 & 11.2 & 2.6 & 0.5 & 1.0 \\
\hline & Difference & 7.2 & 12.5 & 1.7 & 1.2 & 2.2 & 1.5 & 8.6 & 7.3 & 1.6 & -0.3 & 0.2 \\
\hline
\end{tabular}

Source: Initiative for Circular Flow Society (ICFS), 2014 [6]. 
3.4 Changes in the Implementation Reasons between 2010 and 2014

Table 8 shows the changes in the implementation reasons of the environmental activities between 2010 and 2014.

With regard to the implementation reasons of "separating garbage", the rate of "for saving of resources” rose dramatically 21.9\% from 35.1\% in 2010 to $57.0 \%$ in 2014. As for many other activities, such as "turning off electricity as often as possible when not used", “using refillable products" and "saving bath water and tap water" and so on, the rate of "for saving of resources" rose significantly. Presumably this is due to the fact that after 2011's East Japan earthquake disaster, Japan suffered from a serious shortage of energy resources and this was picked up on television and newspapers which changed people's perceptions.

However, as for "bringing a shoppers' own bag instead of a free plastic bag from a shop”, the rate of "for saving of the family budget" increased $12.4 \%$ from $29.6 \%$ in 2010 to $42.0 \%$ in 2014. As for "separating garbage", the rate of "for saving of the family budget” increased $11.3 \%$ during the same period. This is why the charge of the shopping bag in many supermarkets started. In this way, not only environmental benefits but also non-environmental benefits often have promoted the pro-environmental activities.

\subsection{Discussion of Policies}

As the results of the internet investigations stated, in order to tackle the promotion of the environmentally friendly behaviors, we need to raise people's awareness regarding the importance of the environmental issues while seeking the economic efficiency and convenience, including both the effect for environmental load reduction, such as saving resources, and the prevention of global warming and the effect of economy and the social norm.

Based on the above, it is thought to be effective to change the way of the approach for promoting the environmental behaviors by the difference in the degree of the people's concerns about environmental issues.

As showed in Fig. 1, in other words, we need to indicate the environmental effects that the environmental activity have to the highly concerned persons for the environmental issues, such as the leaders of the environmental non-profit organization

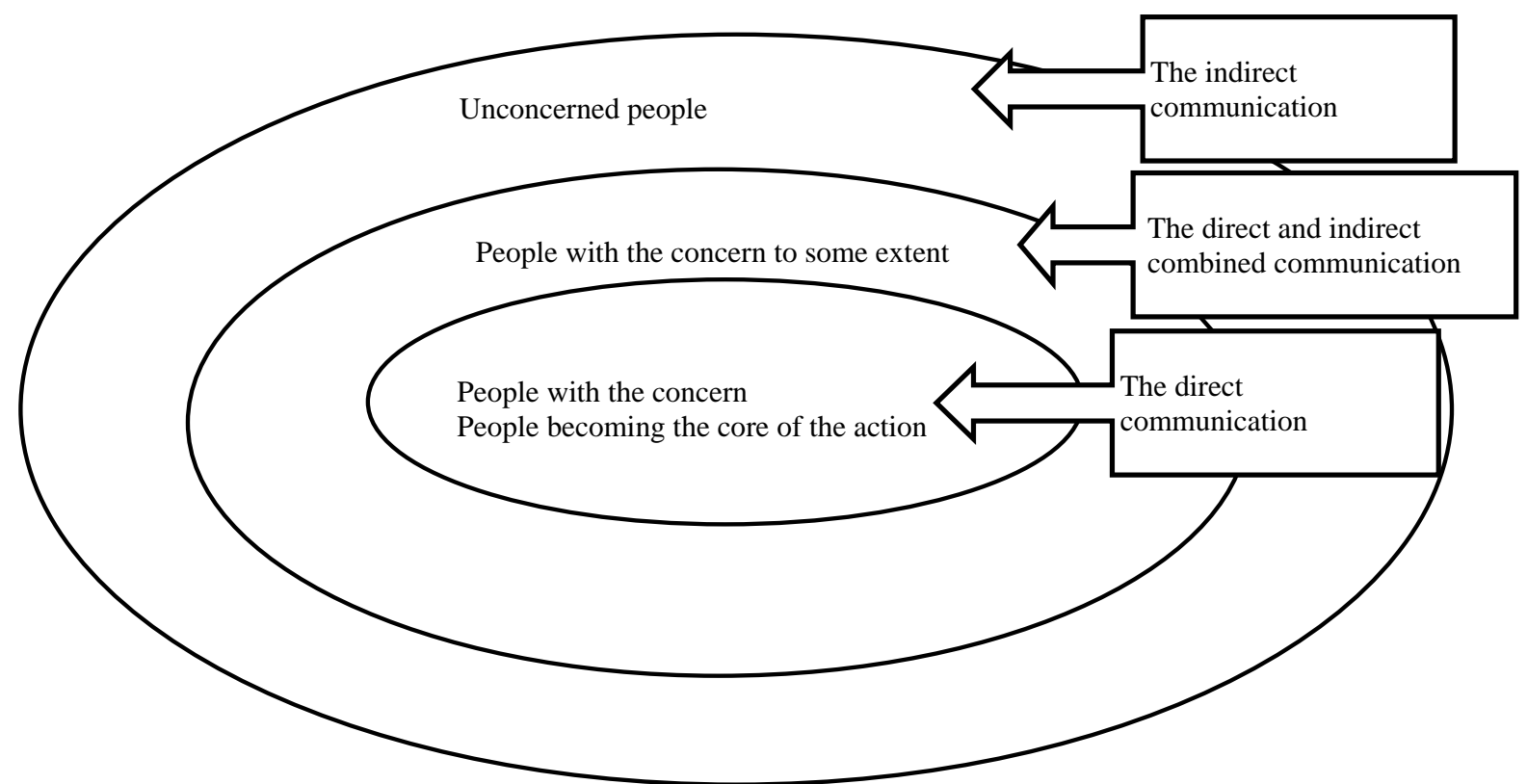

Fig. 1 The relation between the difference of people' concern about the environment and three communication concepts. 


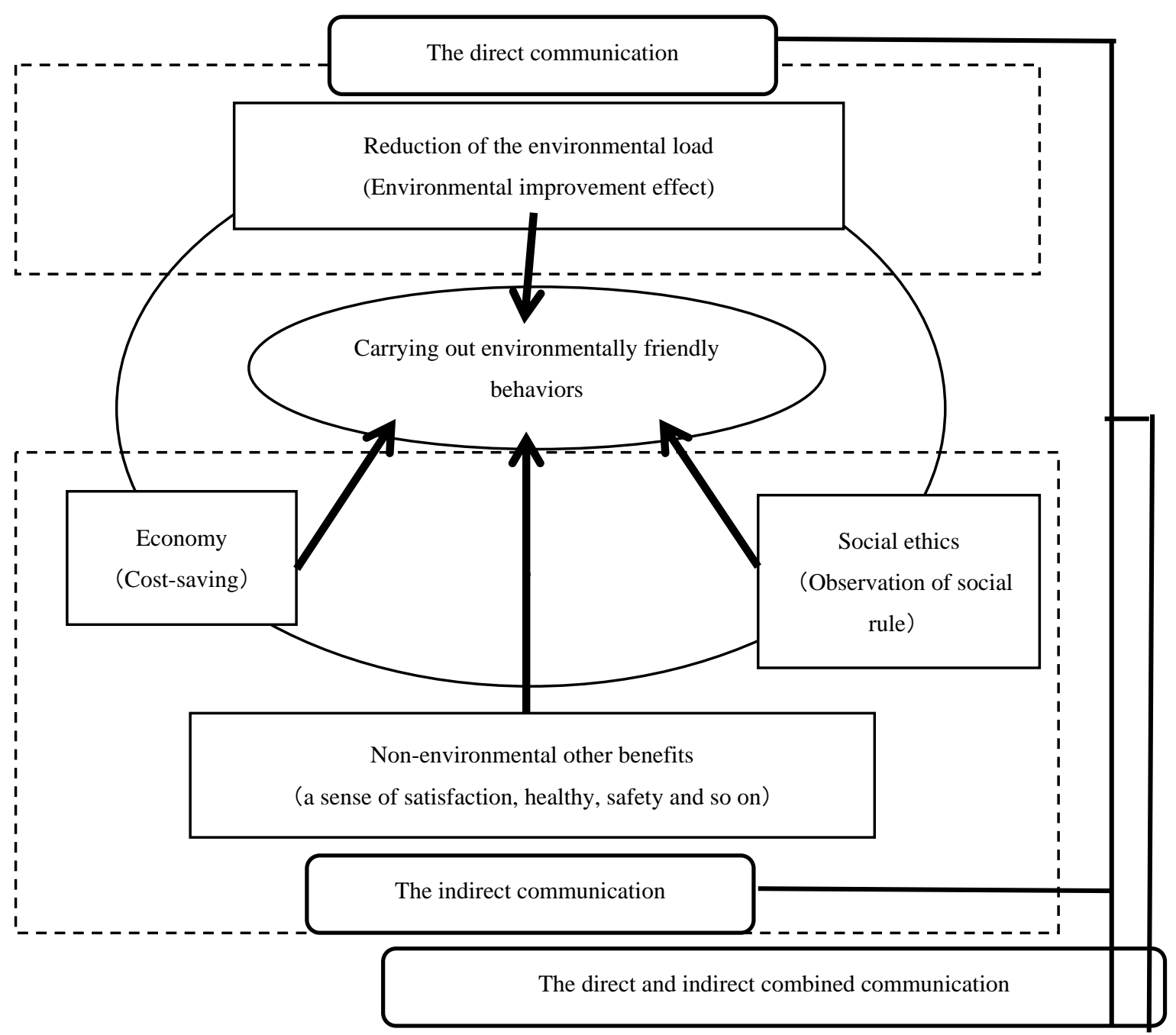

Fig. 2 The relation between three types of communications and various benefits.

(the direct communication), and we should express the non-environmental benefits that the environmental activity have to the unconcerned persons for the environmental issues (the indirect communication).

In addition, it is also thought to be effective for persons interested in the environmental issues to some extent, which the environmental activity have both the environmental effects and non-environmental benefits (the direct and indirect combined communication).

In the results of the internet investigations, cost-saving, a sense of satisfaction, healthy and so on were mentioned as benefits other than the effect for environmental load reduction which promote ambient behavior.

Moreover, it was found that when it came to have recognized the environmental activity as the social rule, such as separating garbage, ambient behavior was tackled from the sense of ethics. Therefore, if the environmental activity is recognized a social rule, appealing to people's sense of ethics as one of the indirect communications is effective.

By using these three kinds of communications properly, ambient behavior is thought to be promoted. The relation between three communications and various benefits is summarized in Fig. 2.

\section{Conclusions}

As described above, the concern about the environmental issues is relatively lower than the rates of pension, social security and economy. As for the 
implementation rate of the environmentally friendly activities, more than $80 \%$ of people responded they always separated garbage, while about only $30 \%$ of people responded they always carried out the reducing standby mode electricity consumption. The implementation rates of the environmentally friendly activities are different by the type of the activities. Also the reasons for carrying out the activities vary in type of activities. The biggest reason of carrying out the "separating garbage" and "bringing a shopper's own bag instead of a free plastic bag offered by a shop" is "for saving of resources". But the biggest reason of "turning off electricity as often as possible when not used" and "adjusting room temperature with a thermostat" and so on is "for saving of a family budget”.

The implementation rates of the environmentally friendly activities in 2014 tended to be declining or remained flat compared to the data in 2010.

Also, the implementation reasons in 2014 were different from the reasons of 2010 when compared. Saving of resources increased $21.9 \%$ in "separating garbage" and in many other activities reason rates rose by more than $10 \%$. "Saving of a family budget" rose $12.4 \%$ in "bringing a shopper's own bag instead of a free plastic bag offered by a shop".

The reason for implementation may change in accordance with change of a social situation or a policy enforcement and so on.

\section{Recommendations and Future's Research}

It is important to increase the implementation rate of the environmentally friendly activities for building the strategy of the administration and the company.

Dealing with the promotion of the environmentally friendly activities is a common challenge for each country. The idea of three type communication, including the utilization of the non-environmental benefits expressing in this article, is effective in each country. The concepts of three types of communication models described herein, including non-environmental benefits, are believed to be beneficial to each country.

In this article, the factors of the environmentally friendly and non-environmentally friendly activities in Japan were analyzed. It will be worth dealing with the solution to the environmental problems to analyze the commonality and difference of the promoting factors for each country and utilize the benefits, including the non-environmental factors.

\section{References}

[1] Ajzen, I., and Fishbein, M. 1980. Understanding Attitudes and Predicting Social Behavior. Upper Saddle River, NJ: Prentice-Hall.

[2] Ajzen, I., and Madden, T. J. 1986. "Prediction of Goal-Directed Behavior: Attitudes, Intentions and Perceived Behavioral Control.” Journal of Experimental Social Psychology 22 (5): 453-74.

[3] Ajzen, I. 1991. "The Theory of Planned Behavior." Organizational Behavior and Human Decision Processes 50 (2): 179-211.

[4] Hirose, Y. 1994. "Determinants of Environment-Conscious Behavior.” The Japanese Society of Social Psychology 10 (1): 44-55.

[5] Ohtomo, S., and Hirose, Y. 2007. "The Dual-Process of Reactive and Intentional Decision-Making Involved in Eco-friendly Behavior.” Journal of Environmental Psychology 27 (2): 117-25.

[6] Initiative for Circular Flow Society (ICFS). 2014. ICFS Researching Report about Environment, Economy and Energy. INTAGE Research Inc., Tokyo.

[7] Statistic Bureau, Ministry of Internal Affairs and Communications. 2005. "The National Population Census 2005.” Accessed February 18, 2016. http://www.estat.go.jp/SG1/estat/GL08020101.do?_toGL 08020101_\&tstatCode $=000001007251 \&$ requestSender $=$ s earch.

[8] Statistic Bureau, Ministry of Internal Affairs and Communications. 2010. "The National Population Census 2010.” Accessed February 18, 2016. http://www.e-stat.go.jp/SG1/estat/NewList.do?tid=00000 1039448.

[9] Nishi, T. 2013. "How to Diffuse Life Cycle Thinking into Agri-Food Industries and Citizens: A Perspective from Consulting Services in Japan.” Present at Regional Conference and Workshop of Life Cycle Thinking on Energy, Food and Agriculture in Asia.

[10] Wikipedia. 2016. "Bankruptcy of Lehman Brothers." Accessed $\quad$ February 19, 2016. 
https://en.wikipedia.org/wiki/Bankruptcy_of_Lehman_Br others.

[11] Wikipedia. 2016. "2011 Tohoku Earthquake and Tsunami.” Accessed February 19, 2016. https://en.wikipedia.org/wiki/2011_T\%C5\%8Dhoku_eart hquake_and_tsunami.

[12] Ministry of Foreign Affairs of Japan. 2007. “G8
Hokkaido Toyako Summit.” Accessed February 17, 2016. http://www.mofa.go.jp/policy/economy/summit/2008/ind ex.html.

[13] Wikipedia. 2016. "Food Safety Incidents in China." Accessed $\quad$ February 2016. https://en.wikipedia.org/wiki/Food_safety_incidents_in_ China. 